\title{
How is Your 8 O'clock Different from Mine? The Accuracy of Public Timekeeping
}

\author{
Aimi Musa, Mustafa Din Subari, Othman Zainon
}

\begin{abstract}
Public timekeeping devices such as analogue watch, digital watch and smart watch give several of accuracy as there are differences between the public time and the standard time. The consequence of having various accuracies in timekeeping is there will be difficulties in having reasonable agreement with other timekeeping devices when it involves public time-reference applications such as attendance system, car parking system, prayer timekeeping as well as making appointments and meetings. In this paper, public timekeeping accuracy has been determined. The data for this study is collected using questionnaire survey, in which the respondents are asked about the information of their timekeeping devices and accuracy. Oneway analysis of variance and independent t-test are used to determine the factors of that impact on public timekeeping accuracy. Our results show that type of timekeeping devices, gender differences and calibration of the devices have significant impacts on public timekeeping accuracy. The findings also indicate that public timekeeping accuracy for this study is 2.07 min (S.D. $\pm 2.20 \mathrm{~min}$ ). Differences ranged from -8.12 to +10.07 minutes, with a median of 1.18 minutes. Overall, this study provides evidence that it is difficult for the public to perfectly match their time with the Malaysian Standard Time. With these findings in mind, policy makers should consider timekeeping accuracy among the public in order to define acceptable range in time-compliance.
\end{abstract}

Keywords: Accuracy, Malaysian standard time, public timekeeping, timekeeping devices.

\section{INTRODUCTION}

Time is a practical necessity to manage activities in daily life such as getting to work on time. Public tell time through their timekeeping devices that will surely give various accuracy. Regulating the timekeeping devices in order to "keep" time accurate presents a great challenge, even with high-quality equipment.

To date, very few studies have been done to investigate the timekeeping accuracy. Most of the studies in literature were specifically done in emergency medical system (EMS) services [1]-[5]. Therefore, most of the literatures on timekeeping studies come from research in medical area. For example, the finding stated in a study published by [5] that more than 50 percent of 152 timekeeping devices used in EMS differed from Coordinated Universal Time (UTC) for one or more minutes. The discrepancies between the timekeeping devices and UTC indicate that even in EMS, error could present, and this leads to life-threatening issues.

Revised Manuscript Received on September 14, 2019.

Aimi Musa, Perdana School of Science, Technology and Innovation Policy, Universiti Teknologi Malaysia, Kuala Lumpur, Malaysia. Email: aimimusa318@gmail.com

Mustafa Din Subari, Perdana School of Science, Technology and Innovation Policy, Universiti Teknologi Malaysia, Kuala Lumpur, Malaysia.E-mail: m.subari@utm.my

Othman Zainon, Department of Geoinformation, Faculty of Built Environment and Surveying, Universiti Teknologi Malaysia, Johor Bahru, Malaysia. E-mail: othmanz.kl@utm.my
Consequently, it is certainly necessary to determine the timekeeping accuracy among the public. The reason is that, timekeeping accuracy could be important not only in medical services but also when involves some important public time-reference applications (Fig. 1) such as appointments and meetings [6], attendance system [6], transportation [7], and prayer timekeeping [8]. These timereference applications have been used by the public all over the world.

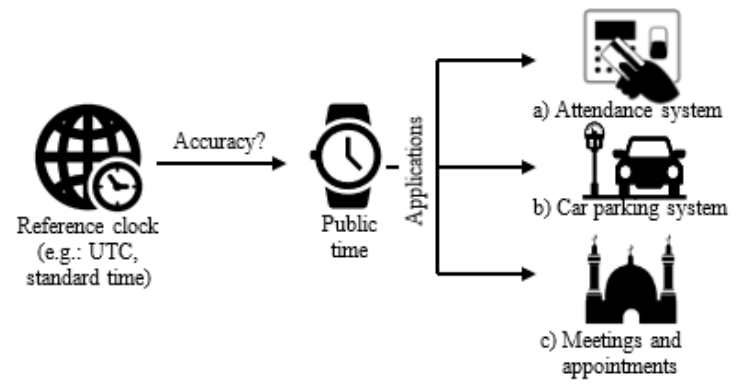

Fig.1. Example of public time-reference applications

The objectives of this paper are to investigate the public timekeeping accuracy and to examine the factors that contribute to the difference between public time and reference time. The paper begins with a review of existing literature about public timekeeping, timekeeping devices and standard time used specifically in Malaysia. It then presents the data used for the analysis and describes the results of public timekeeping accuracy. Lastly, the paper concludes with a discussion of the findings and proposes suggestions for future public timekeeping accuracy studies.

\section{LITERATURE REVIEW}

\section{A. Public Timekeeping}

Time can be defined as a physical quantity observed and calculated using timekeeper system known as mechanical clock, electrical clock and physical nature [6], [9]. Timekeeping can be defined as the act of using physical processes to measure and track time or frequency. Precise timekeeping, dissemination and synchronization have been some of the most essential technological errands for several centuries [10], [11].

Personal timekeeping devices used by public in their daily life deviate from the reference time such as UTC and they resulted in the difference of time. It is financially impractical to build atomic clocks set to UTC into all type of timekeeping. It is commonly understood that device with better accuracy and stability is usually built by a more

\section{Published By:}

Blue Eyes Intelligence Engineering

\& Sciences Publication 
expensive system. Differences can also be seen in time devices that are using similar system. As stated by [12] in his paper, two or more independent clocks are unable to keep the exact same time, and this can be proved by synchronizing a group of wristwatches and then check them again a month later. The wristwatches will show different times from each other by at least a few seconds. A group of cesium clocks can also be measured using the same method, and the time difference will be small, nanoseconds instead of seconds, but again, the clocks would not keep the perfect similar time [12]-[14].

\section{B. Public Timekeeping Devices}

Historically, mankind was only counting time in the unit of days. It is a big timescale and varies according to the season. Since that, there are various inventions of clocks to carve the time of the day into shorter and more uniform increments. A clock is what does the counting of cycles or units of time. Time is measured by scales and users for different purposes, where the scales have been adjusted in order to meet changing needs or to improve accuracy [6].

Nowadays, there are various types of timekeeping devices that have been invented and used by the public for daily activities. Common examples include the digital watch, analogue watch, as well as smartwatch. These types of devices are dependable and easier to use and nearly everyone will look at the devices in order to get information of "What time is it?". Each of the timekeeping devices has its own accuracy. Time accuracy can be defined as how well a timekeeping device agrees with UTC. In other words, time accuracy is depending on the synchronization of a timekeeping device to UTC [13].

\section{Standard Time in Malaysia}

In Malaysia, National Metrology Institute of Malaysia, SIRIM, was assigned by the Malaysian Cabinet on August 5, 1992 to be the national timekeeper (refer to Cabinet Note $\mathrm{H}$ 226/92) in which the Malaysia local time is officially named as Malaysian Standard Time (MST) (Fig. 2). SIRIM is responsible for maintaining the time interval standards, establishing the national atomic scale and defining and maintaining the regional UTC established by the BIPM as UTC (NLMS). In order to detect any abnormality or instability, the national atomic time scale is developed and maintained using five cesium atomic clocks which are compared to each other. The Malaysian atomic time scale is traceable to the International Atomic Time (TAI) due to its participation in the International Bureau of Weights and Measures GPS common view time transfer [15].

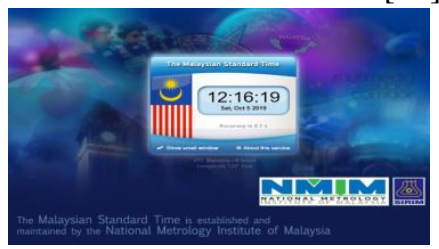

Fig.2. The figure above shows the example of MST clock from the website (Source: http://mst.sirim.my/)

\section{METHODOLOGY}

\section{A. Questionnaire Surveys}

The survey used for this study was adapted from the study done by [4]. An online survey and face-to-face survey were conducted on January 2019 until June 2019. The questions were used for covering the various aspects of public timekeeping pertaining to the topic which include public timekeeping devices used by the public and calibration of their timekeeping devices. For the last question, a fill in question was asked about the accuracy of public timekeeping. The questions were created with minimum ambiguities, using clear and precise language. Thirty $(n=30)$ persons were adequate to answer the questionnaire regardless of their background as pilot study. The face-toface survey questionnaire required self-completion by the public with the assistance of researcher. The pilot test suggested that the questionnaire was clear and understandable.

\section{B. Sample Study}

As the demographics of Malaysia are reflected by various ethnics, the three largest ethnics were selected for this study, which is Malay, Chinese and Indian (3). They sum up to almost $90 \%$ of the total 32.58 million population of this country excluding the non-citizens. The demographic compositions in Malaysia for 2019 are as follows; $62.5 \%$ of the populations are Bumiputera, $20.6 \%$ are Chinese and Indians account for $6.7 \%$.

Initially, 940 respondents involved in this study whom are randomly selected using online survey approach and face-toface survey. The online survey approach was chosen because it yields a higher response rate and the time taken to obtain the required data is faster [16]. Nevertheless, a total of 879 data out of 940 were valid for further analysis. 61 responses were removed as they were detected as outliers.

\section{Demographics}

Table I shows a list of the respondents' demographic characteristics. Respondents for this study consist of $45.5 \%$ male and $54.5 \%$ female. The respondents' age ranged between 20 and 30 years $(60.8 \%)$, between 31 and 40 years $(19.7 \%)$, between 41 and 50 years $(10.8 \%)$, and the remaining are aged above 50 years. This study is also represented by respondents who are working in government and private sector (63.3\%), self-employed (8.1\%), unemployment $(8.3 \%)$ and students $(20.4 \%)$. A majority of the respondent $(76.1 \%)$ is Malay, and $17.4 \%$ and $6.5 \%$ are Chinese and Indian respectively. 
Table- I: Respondents' demographics

\begin{tabular}{|c|c|}
\hline Demographics & Percent \\
\hline a) Gender & 45.5 \\
Male & 54.5 \\
Female & \\
\hline b) Age & 60.8 \\
20-30 years & 19.7 \\
31-40 years & 10.8 \\
41-50 years & 8.7 \\
51 and above & \\
c)Occupation & 63.3 \\
Employed & 8.1 \\
Self-employed & 8.3 \\
Unemployed & 20.3 \\
Student & \\
\hline d) Race & 76.1 \\
Malay & 17.4 \\
Chinese & 6.5 \\
Indian & \\
\hline
\end{tabular}

\section{Procedure}

Respondents were asked to capture a photo of their timekeeping devices that display the time and MST in order to get the information about their timekeeping accuracy. Fig. 3 shows the example of photo captured by one of the respondents. This is to avoid error while reading and recording the time. Besides this method is used to make sure that the time was recorded accurately [17]. The accuracy of the MST clock was initially checked before capturing the photo to make sure it is \pm 0.1 seconds accuracy.

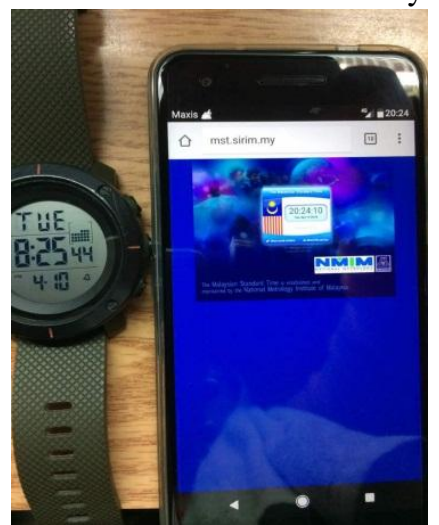

Fig.3. Example of photo captured by one of the respondents

The difference was calculated by comparing the time shown by each public timekeeping devices and MST. The timekeeping accuracy, denoted by $\Delta \mathrm{t}$, refers to the degree of correctness of the time displayed by public timekeeping device, $\mathrm{t}$ and MST, $\mathrm{t}_{\mathrm{o}}$.

$$
\Delta \mathrm{t}=\left|\mathrm{t}-\mathrm{t}_{\mathrm{o}}\right|
$$

\section{E. Data Analysis}

The error of each timekeeping device sampled during each survey was measured and entered into Microsoft Excel (Microsoft Corporation). Intended for the calculation of means, standard deviations and median the absolute values of the time differences were utilized to avoid the problem of negative (slow) and positive (fast) times canceling each other [2].

Data were analyzed using descriptive statistics, one-way analysis of variance (ANOVA) for evaluating differences among type of timekeeping devices and two tailed independent samples t-test for difference between two means. The result is said to be statistically significant if $P \leq$ 0.05. Statistical analysis was performed using Stata versions 14 (StataCorp).

\section{RESULTS AND DISCUSSION}

The analysis focuses on the public timekeeping accuracy by type of timekeeping devices, gender as well as the calibration of public timekeeping devices. Table II shows the results of the public timekeeping accuracy by the type of timekeeping devices analyses using ANOVA and 95\% confidence intervals (CI). Table III and IV show the results of the public timekeeping accuracy by gender and calibration of the timepieces analyses using independent $t$ test and $95 \%$ CI respectively.

\section{A. Accuracy of Public Timekeeping Devices}

A total of 879 timekeeping devices were evaluated and compared to MST. Fig. 4 shows that of the 879 respondents surveyed, $534(60.75 \%)$ reported using analogue watches, $315(35.84 \%)$ respondents reported using digital watches and $30(3.41 \%)$ respondents reported using smartwatches.

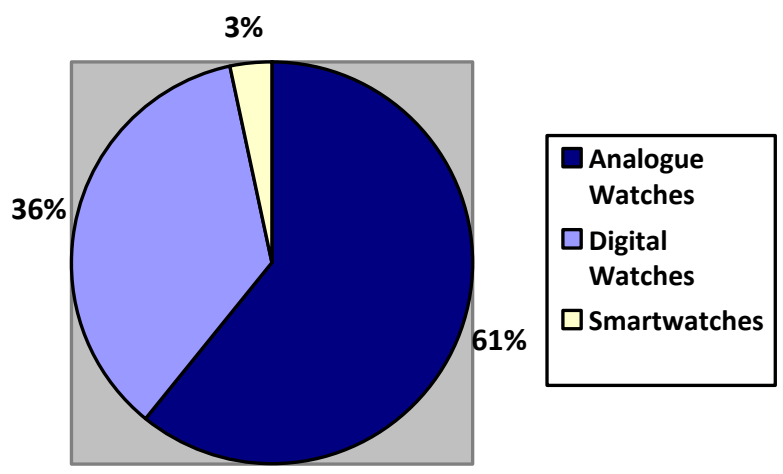

Fig.4. Type of timekeeping devices used by the public

Table II displays the variations from MST for public timekeeping devices; analogue watches, digital watches and smartwatches. One-way ANOVA has been used to determine whether the accuracy of timekeeping device can be influenced by type of timekeeping device. The results of the study present significance difference among the three types of timekeeping devices $(P<0.05)$.

A total of 534 analogue watches were evaluated for accuracy, and the results show that $2(0.37 \%)$ analogue watches were similar with the MST. Differences ranged from -7.10 to +10.07 minutes, with a median of 1.35 minutes. The absolute mean time difference from MST was 2.37 minutes, with a standard deviation of 2.35 minutes.

For digital watches, a total of 315 were evaluated for accuracy, with $23(7.30 \%)$ showing the same time as MST. Differences ranged from -8.12 to +7.15 minutes, with a median of 0.82 minutes. The absolute mean time difference from MST was 1.73 minutes, with a standard deviation of 1.89 minutes.

Of the 879 respondents, 30 respondents used smartwatches as their timepieces, and the data were evaluated for accuracy, with $12(40.00 \%)$ showing the same

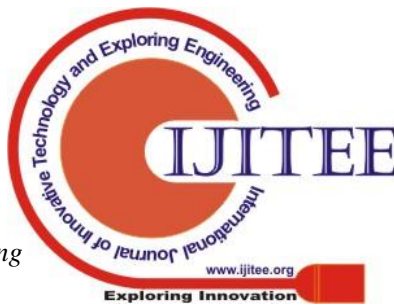


time as MST. Differences ranged from -0.93 to +0.37 time difference from MST was 0.32 minutes, with a minutes, with a median of 0.15 minutes. The absolute mean

standard deviation of 0.35 minutes.

Table- II: Variations from MST for timekeeping devices used by the public

\begin{tabular}{|c|c|c|c|c|c|c|c|}
\hline $\begin{array}{l}\text { Timekeeping } \\
\text { Devices }\end{array}$ & Observations & Mean \pm S.D. $*(\min )$ & Median (min) & Range & Slow & Fast & Exact \\
\hline Analogue watches & 534 & $2.37 \pm 2.35$ & 1.35 & -7.10 to +10.07 & $179(33.52)$ & $353(66.10)$ & $2(0.37)$ \\
\hline Digital watches & 315 & $1.73 \pm 1.89$ & 0.82 & -8.12 to +7.15 & $168(53.33)$ & $124(39.37)$ & $23(7.30)$ \\
\hline Smartwatches & 30 & $0.32 \pm 0.35$ & 0.15 & -0.93 to +0.37 & $14(46.67)$ & $4(13.33)$ & $12(40.00)$ \\
\hline
\end{tabular}

Values in parentheses are percentages; S.D.: standard deviation; -: slow; +: fast.

* $P<0.05$ (ANOVA)

Hence, of 879 timekeeping devices, only 37 timekeeping devices were accurate according to the MST; $2(0.37 \%)$ analogue watches, $23(7.30 \%)$ digital watches and 12 (40.0\%) smartwatches. Three hundred and sixty-one $(41.07 \%)$ of the 879 timekeeping devices were slow, 535 $(60.86 \%)$ were fast and $37(4.21 \%)$ were exact overall.

The findings from this study confirm that the smartwatch is the most consistent timekeeping device with the MST. This was not necessarily an unexpected observation considering its integrated sensors and clock which frequently linked with the Internet or other devices [18]. In other words, the advantage of smartwatch to connect with other devices or Internet provides benefit to the user in term of accurate time as it is in synch with reference clock compared to analogue watch and digital watch. As long as it is connected to a network, time synchronization can be regularly updated thus, increasing the accuracy. As stated by [12], the accuracy of the timekeeping device would be better if the synchronization were automatic.

\section{B. Public Timekeeping Accuracy Based on Gender}

An independent t-test has been computed to measure mean difference of public timekeeping accuracy based on gender (Table III). The finding demonstrated there is a significant mean difference of public timekeeping error based on calibration of the timekeeping devices [DF = 876.451, $\mathrm{t}=-2.207, P<0.05]$.

Table- III: Public timekeeping accuracy by gender

\begin{tabular}{|l|l|l|}
\hline Gender & Observations & $\begin{array}{l}\text { Mean } \\
\text { S.D.*(min) }\end{array}$ \\
\hline Male & $400(45.51)$ & $1.89 \pm 2.01$ \\
\hline Female & $479(54.49)$ & $2.21 \pm 2.34$ \\
\hline
\end{tabular}

Values in parentheses are percentages; S.D.; standard deviation.

\section{$* P<0.05$ (Independent $t$-test)}

According to the above results, male respondents $(1.89 \pm$ $2.01 \mathrm{~min})$ are more accurate in term of timekeeping accuracy compared to female respondents $(2.21 \pm 2.34 \mathrm{~min})$. To the best of author's knowledge, to date, no study investigated timekeeping accuracy in male and female. However, the results seen in the present study are in line with those of several studies on gender differences in time perception [19], time estimation [20], and reaction time [21], [22]. Although the findings in previous studies and present study shown that men are more accurate than women in time, on average, it has been concluded by many reviewers of gender differences that female is better than male on some verbal tasks whereas male is better than female on some spatial tasks [23].

\section{Calibration of Public Timekeeping Devices}

A total of $642(73.04 \%)$ respondents calibrate their timekeeping devices and $237(26.96 \%)$ respondents did not calibrate their timekeeping devices (Fig. 5). An independent t-test has been computed to measure mean difference of public timekeeping accuracy based on calibration of the timekeeping devices. The findings demonstrate that there is a significant mean difference of public timekeeping accuracy based on calibration of the timekeeping devices $[\mathrm{DF}=358.336, \mathrm{t}=-1.149, P<0.05]$.

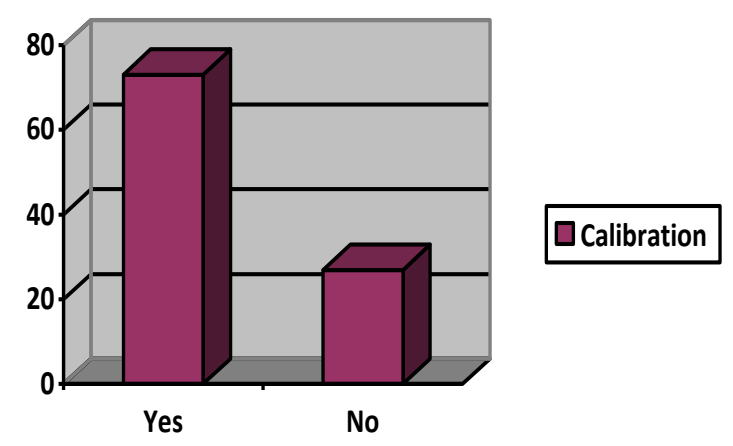

Fig.5. Percentage of respondents based on calibration of timekeeping devices

By referring at the mean values, the mean score of public timekeeping error among the respondents for who choose 'No' (2.23 $\pm 2.53 \mathrm{~min})$ significantly higher than who choose 'Yes' $(2.01 \pm 2.06 \mathrm{~min})$ in term of calibration of timekeeping devices.

Table- IV: Calibration of timekeeping accuracy by gender

\begin{tabular}{|l|l|l|}
\hline $\begin{array}{l}\text { Calibration of } \\
\text { Timekeeping Devices }\end{array}$ & Observations & $\begin{array}{l}\text { Mean } \\
\text { S.D.*(min) }\end{array}$ \\
\hline Yes & $642(73.04)$ & $2.01 \pm 2.06$ \\
\hline No & $237(26.96)$ & $2.23 \pm 2.53$ \\
\hline
\end{tabular}

Values in parentheses are percentages; S.D.; standard deviation.

$* P<0.05$ (Independent $t$-test)

According to the results in Table IV, respondents who calibrate their timekeeping devices have better accuracy compared with the respondents who did not calibrate their timekeeping devices. This accuracy difference may be explained by the fact that the calibration of a timekeeping device may slow the process of clock drift although it could never eliminate the error continuously [14].

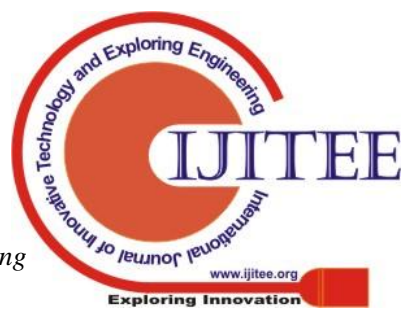




\section{Overall Public Timekeeping Accuracy}

The mean absolute difference from MST was $2.07 \mathrm{~min}$ (S.D. $\pm 2.20 \mathrm{~min}$ )and the median absolute difference was $1.18 \mathrm{~min}$. Time deviations from MST clock have been reported to range widely from $-8.12 \mathrm{~min}$ to $+10.07 \mathrm{~min}$. Some studies have examined the timekeeping accuracy in medical service system. A representative study by [1] quantified the timekeeping error of emergency medical services (EMS) system staff is two minutes before the synchronization to the atomic clock standard. In that study, timekeeping devices used by EMS staff; firefighters, paramedics, emergency physicians and nurses were randomly sampled by comparing each timekeeping device with the atomic clock. Another study on timekeeping accuracy was done by [5] shows that the accuracy of timekeeping device in EMS was 1.45 minutes.

In the present study, the same method as previous studies was used to determine the timekeeping accuracy but with a different sample population. The timekeeping accuracy specifically for the public was defined as the absolute difference between the time shown by public timekeeping devices; analogue watch, digital watch and smartwatch and the time shown by MST clock. The standard errors presented by the public timekeeping devices in this study demonstrate the public timekeeping accuracy. In [24] mentioned that accuracy of a timekeeping device is related to the difference between measured value and an actual value.

The timekeeping accuracy determined in this study indicates that it is impossible for all timekeeping device to have perfectly exact time as MST. This has been explained by [13] in their book which setting the clock in practical could deviate from the idealism of clock setting principle. Ideally, if a timekeeping device has been set correctly and if the frequency of the timekeeping device remained perfect, the accuracy can be maintained indefinitely. However, in reality, due to the fact that each of timekeeping devices has its own errors, it is difficult to get perfectly accurate time for the timekeeping devices.

It has been an incredible achievement to measure time accurately in a smaller time scale. However, as human try to compress more tasks in this smaller interval, they become too dependent to the accuracy of time. Frank Hope-Jones, one of the famous horologists, once wrote that 'the root of the evil in timekeeping' was the independence of clock [25].

\section{CONCLUSION}

In conclusion, the findings of this study indicate that the public timekeeping accuracy is $2.07 \mathrm{~min}$ (S.D. $\pm 2.20 \mathrm{~min}$ ). The results show that timekeeping accuracy is significantly influenced by type of timekeeping devices, gender, and calibration of the timekeeping devices. This study indicates analogue watches have the highest absolute error compared to digital watches and smartwatches. While it is possible to get greater accuracy by using smartwatches, out of 879 respondents, $534(60.75 \%)$ respondents using analogue watches.

This study also presents evidence that male respondents have better timekeeping accuracy than female respondents. Results from this study also indicate that respondents who calibrate their timekeeping device are associated with better accuracy than the one who do not calibrate their timekeeping devices.

Future studies should focus more on many other factors that could contribute to the public timekeeping accuracy, such as frequency of timekeeping device calibration and reference used to synchronize the timekeeping device. Finally, timekeeping accuracy among the public should be considered by the policy makers in order to define range of acceptable leeway in time compliance.

\section{REFERENCES}

1. Ornato, Joseph P., Mark L. Doctor, Lori F. Harbour, Mary Ann Peberdy, Jerry Overton, Edward M. Racht, William G. Zauhar, Alan P. Smith, and Kent A. RyanII. "Synchronization of timepieces to the atomic clock in an urban emergency medical services system." Annals of Emergency Medicine 31, no. 4 (1998): 483-487.

2. Kaye, William, Mary Elizabeth Mancini, and Tanya Lane Truitt. "When minutes count - the fallacy of accurate time documentation during in-hospital resuscitation." Resuscitation 65, no. 3 (2005): 285-290.

3. Brabrand, Mikkel, Susanne Hosbond, Dan Brun Petersen, Alice Skovhede, and Lars Folkestad. "Time telling devices used in Danish health care are not synchronized." Dan Med J 59 (2012): A4512.

4. Ferguson, Elizabeth A., Carey Roth Bayer, Susan Fronzeo, Cheryl Tuckerman, Larissa Hutchins, Kathryn Roberts, Judy Verger, Vinay Nadkarni, and Richard Lin. "Time out! Is timepiece variability a factor in critical care?." American Journal of Critical Care 14, no. 2 (2005): 113-120.

5. Cordell, William H., Michael L. Olinger, Paul A. Kozak, and Allen W. Nyhuis. "Does anybody really know what time it is? Does anybody really care?." Annals of Emergency Medicine 23, no. 5 (1994): 1032-1036.

6. Jespersen, James, and Jane Fitz-Randolph. From sundials to atomic clocks: understanding time and frequency. Courier Corporation, 1999.

7. Jurišić, Darko, Niko Jelušić, and Marko Matulin. "Measurement of public transport performance indicators by PDA computer system." 19th International Symposium on Electronics in Traffic, 2011.

8. Hashim, Rathiah, Mohammad Sibghotulloh Ikhmatiar, Miswan Surip, Masiri Karmin, and Tutut Herawan. "A mobile GPS application: Mosque tracking with prayer time synchronization." International Conference on Future Generation Communication and Networking, pp. 237-246, 2010.

9. Messerschmitt, David G. "Relativistic timekeeping, motion, and gravity in distributed systems." Proceedings of the IEEE 105, no. 8 (2017): 1511-1573.

10. Bauch, Andreas, Joseph Achkar, S. Bize, Davide Calonico, Rolf Dach, R. Hlavać, Luca Lorini et al. "Comparison between frequency standards in Europe and the USA at the 10- 15 uncertainty level." Metrologia 43, no. 1 (2005): 109.

11. Levine, Judah. "A review of time and frequency transfer methods." Metrologia 45, no. 6 (2008): S162.

12. Lombardi, Michael A. "The evolution of time measurement, Part 5: radio controlled clocks [Recalibration]." IEEE Instrumentation \& Measurement Magazine 15, no. 2 (2012): 49-55. 
13. Allan, David W., Neil Ashby, and Clifford C. Hodge. The science of timekeeping. Hewlett-Packard, 1997.

14. Weiss, Marc A., David W. Allan, Dick D. Davis, and Judah Levine. "Smart clock: a new time." IEEE Instrumentation and Measurement Technology Conference, pp. 38-41, 1992.

15. SIRIM, "The Malaysian Standard Time." [Online]. Available: http://mst.sirim.my/.

16. D. R. Cooper and P. S. Schindler, Business research methods, 11th editi. New York: McGraw-Hill//rwin, 201AD.

17. Musa, Aimi, Mustafa Din Subari, and Othman Zainon. "Synchronization of public timekeeping devices in Malaysia to Malaysian standard time." IEEE 15th International Colloquium on Signal Processing \& Its Applications, pp. 31-34, 2019.

18. Bieber, Gerald, Thomas Kirste, and Bodo Urban. "Ambient interaction by smart watches." ACM 5th International Conference on Pervasive Technologies Related to Assistive Environments, p. 39, 2012.

19. Hanson, Nicholas J., and Janet Buckworth. "Sex differences in time perception during self-paced running." International Journal of Exercise Science 9, no. 4 (2016): 514.

20. Block, Richard A., Peter A. Hancock, and Dan Zakay. "Sex differences in duration judgments: A meta-analytic review." Memory \& Cognition 28, no. 8 (2000): 13331346.

21. Reed, T. Edward, Philip A. Vernon, and Andrew M. Johnson. "Sex difference in brain nerve conduction velocity in normal humans." Neuropsychologia 42, no. 12 (2004): 1709-1714.

22. Dykiert, Dominika, Geoff Der, John M. Starr, and Ian J. Deary. "Sex differences in reaction time mean and intraindividual variability across the life span." Developmental Psychology 48, no. 5 (2012): 1262.

23. Sanders, Geoff, and Kamila Sinclair. "Sex differences in accuracy and precision when judging time to arrival: data from two internet studies." Archives of Sexual Behavior 40, no. 6 (2011): 1189-1198.

24. Lombardi, Michael A. "The accuracy \& stability of quartz watches." Horological Journal 150, no. 2 (2008): 57.

25. Lombardi, Michael A. "Radio Controlled Wristwatches." Horological Journal 148, no. 5 (2006): 187.

\section{AUTHORS PROFILE}

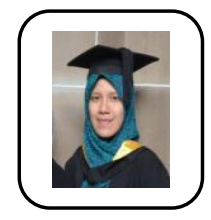

Aimi Musa is a $\mathrm{PhD}$ student at the Perdana School, Razak Faculty of Technology and Informatics, UniversitiTeknologi Malaysia. Her current doctoral research investigates the impact of public timekeeping accuracy towards the public time-reference application Her research interests include information technology and astronomy. She holds a master's degree in Geographic Information Technology from the University of Melbourne, Australia and bachelor's degree in Geomatic Engineering from UniversitiTeknologi Malaysia, Johor Bharu.

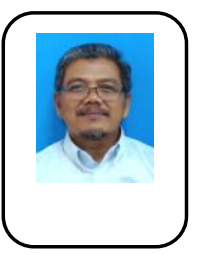

DrMustafa Din Subari is a Professor at the Perdana School of STI Policy Studies, Razak Faculty of Technology and Informatics, UniversitiTeknologi Malaysia, Kuala Lumpur, Malaysia. Apart from involvement in GNSS sector, his research interest is STI Policy particularly in space policy and astronomy. He was Malaysia's National Space Agency (ANGKASA) Director-General in 2008-2013 and the Deputy DirectorGeneral in 2006-2007. He holds bachelor's degree in Land Surveying from UTM, master's degree in Geodetic Sciences from The Ohio State University and PhD in GPS Surveying from UNSW, Australia.

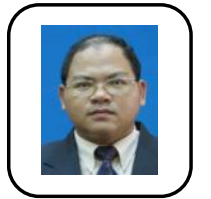

DrOthman Zainon is a Senior Lecturer at the Department of Geoinformation, Faculty of Built Environment and Surveying, UniversitiTeknologi Malaysia, Johor Bahru, Malaysia. His teaching experiences for more than ten years are about, astronomy, basic geodesy, cadastral survey, engineering survey and many other related subjects. More than hundred technical papers were published in journal, proceeding as well as book chapter. He holds bachelor's degree and master's degree in Land Surveying inUniversitiTeknologi Malaysia. He also graduated with a PhD in Geomatic Engineering at the same university. 